\title{
Apresentação
}

\section{Lexicografia Pedagógica}

Claudia Zavaglia

Odair Luiz Nadin

A Lexicografia Pedagógica, como disciplina autônoma, vem se firmando nos últimos anos de forma cada vez mais consistente e crítica. Seu foco recai sobre a investigação dos dicionários produzidos com finalidades pedagógicas, ou seja, aqueles para aprendizes e/ou escolares.

Duas de suas características principais podem ser, resumidamente, assim descritas: a escolha e definição de um público específico, no caso, o aprendiz de língua, e de um escopo próprio, qual seja, a aprendizagem de uma língua, seja ela materna ou estrangeira. Seus objetos de estudo abarcam, principalmente, a análise crítica, a elaboração e o uso dos dicionários ditos pedagógicos.

Concentrar a atenção no consulente do dicionário é o ponto central da Lexicografia Pedagógica, e, consequentemente, a elaboração desses repertórios linguísticos passa a ser um de seus principais propósitos. Dessa forma, visto como uma ferramenta linguística para o aprendiz de língua, o dicionário pedagógico tem como mote primordial a função didática no aprendizado das línguas.

Em relação aos termos "Lexicografia Pedagógica" e "Lexicografia Didática", temos que a primeira se revela como uma área de estudos e pesquisas, dedicando-se aos dicionários que se voltam às escolas, os denominados "dicionários escolares". Segundo Teixeira (2015), esse tipo de dicionário é “determinante da lexicografia didática, no entanto, a lexicografia pedagógica, vai além do estudo da produção de 
dicionários escolares", uma vez que "engloba a produção, a avaliação e a investigação desses dicionários, sendo tanto prática quanto teórica" (p. 34).

Foi com o intuito de revelar e de concretizar as tendências contemporâneas, além de promover e instigar o debate sobre os desafios e os avanços obtidos nessa área com relação às pesquisas descritivas e aplicadas em distintas situações de uso, que propusemos o presente número temático.

São 18 artigos inéditos e uma entrevista com uma das mais renomadas pesquisadoras em Lexicografia, a Profa. Dra. Maria Teresa Fuentes Morán.

\section{Um pouco de história}

Segundo Molina García (2006, pp.14-15), a Lexicografia Pedagógica passa a existir a partir do momento que alguns professores se dão conta de que o dicionário para um aprendiz não pode ser o mesmo dicionário elaborado para um nativo da língua e que, portanto, se o consulente é um aprendiz, essa obra deverá se adaptar e se moldar ao seu nível e às suas necessidades linguísticas, quer dizer: um usuário que não tem domínio da língua e que, desse modo, precisará de toda a sorte de ajuda ao tratá-la e ao manejá-la.

Esse mesmo autor reporta que foi necessário chegarmos aos anos 30 para que houvesse o que ele chamou de "Revolução lexicográfica-pedagógica". E foi também no início do séc. XX que os olhares de pesquisadores se voltaram para o léxico de uma língua e passaram a enxergá-lo como um expediente pedagógico no ensino de uma língua estrangeira, por exemplo. De fato, deu-se início à produção das chamadas listas de palavras essenciais ou básicas para a aprendizagem de uma língua, o que motivou, sem dúvida, o florescer dos primeiros dicionários pedagógicos.

Mariana Daré Vargas contribui para este volume com o artigo intitulado Lexicografia Pedagógica: história e panorama em contexto brasileiro, no qual resgata, justamente, o "nascimento" da Lexicografia Pedagógica, a partir da mudança de 
paradigmas do ensino de línguas que refletiu diretamente na ciência da Lexicografia, uma vez que a abordagem "do léxico e da gramática nos dicionários voltados ao ensino" deveria "satisfazer as necessidades de aprendizagem dos usuários". Reportanos, também, autores como Henry Sweet, que em 1899 publicou o texto $O$ dicionário: estudo do vocabulário e passou a ser tido como o marco inicial das pesquisas em Lexicografia Pedagógica, além de “Thorndike (1928), Odgen, Harold Palmer, Michael West e A. S. Hornby (década de 1930), L. V. Ščerba (1940), Zgusta (1971), Dubois e Dubois (1971), Hausmann (1974, 1977, 1989), Wiegand (1977), Kromann, Riber e Rosbach (1984)", que no decorrer do século XX "abordaram questões relacionadas ao dicionário no ensino-aprendizagem de língua(s), especialmente no âmbito da língua inglesa". A partir disso, traça um panorama da Lexicografia Pedagógica, "de Hartmann (1992) a De Schryver (2012), em cenário nacional e internacional".

\section{Um pouco de prática}

Os dois seguintes textos tratam de experiências práticas no âmbito da Lexicografia Pedagógica. O primeiro intitulado Lexicografia Pedagógica: uma proposição prática exemplificada, de Maria da Graça Krieger e Alexandra Feldekircher Müller, versa sobre a publicação do Caderno Interativo: atividades com o dicionário, publicado em 2017 e de autoria das duas autoras do texto. Trata-se da proposição de exercícios que relaciona habilidades e competências que são exigidas no ensino da língua portuguesa, tanto para a leitura, quanto para a produção textual, com o uso do dicionário. As autoras pontuam que no panorama brasileiro, com as políticas linguísticas implantadas pelo Ministério da Educação, com o Programa Nacional do Livro Didático (PNLD), houve grande impulso e impacto para a elaboração de dicionários preocupados com o consulente aprendiz e que estudiosos das Ciências do Léxico e lexicógrafos passaram a atentar para uma organização dessas obras que fosse compatível com os níveis de aprendizagem dos usuários em nível escolar, do 
fundamental ao ensino médio, bem como com a adequação "da proposta lexicográfica de cada tipo de obra". Como deduzem as autoras: "o dicionário, pelo conjunto de informações que oferece, é uma obra que ultrapassa de longe a ideia de simples listagem de palavras a que se agregam significados e algumas informações gramaticais"

Já o texto Lexicografia Pedagógica: um relato da experiência do uso de dicionários para ensinar italiano a um grupo da 'melhor idade', de Fábio Henrique de Carvalho Bertonha, relata a experiência do autor junto ao Centro Universitário da Fundação Educacional de Barretos (UNIFEB), que ministra aulas de língua italiana para estudantes da terceira idade, nas quais promove a aproximação desses alunos com o dicionário. Várias atividades de ensino junto ao dicionário são apresentadas aos alunos: provérbios, cores, numerais, pronúncia, tradução, entre outras e com elas, nas palavras do autor, é possível entender que o "dicionário serve como aporte para o deslocamento de práticas nas quais a leitura seja extração de um sentido estabilizado no verbete apresentado, pois é um tipo de obra que pode ser tomada em seus aspectos linguísticos, políticos, sociais, culturais, históricos ao registrar como o léxico, ao longo do tempo, transforma-se ou se mantém, trazendo à tona outros e novos sentidos".

\section{Um pouco de interdisciplinaridade}

Assim como a Lexicografia, a Lexicografia Pedagógica é uma ciência interdisciplinar que mantém relações com diversas outras áreas ou subáreas.

Em Lexicografia pedagógica da língua portuguesa e Dialetologia: tecendo redes de conhecimento, Marcela Moura Torres Paim e Isamar Neiva Santana refletem a importância da Dialetologia no feitio de dicionários escolares. De fato, segundo as autoras, "A importância da inclusão de informações geolinguísticas em dicionários está relacionada ao fato de que uma obra desse teor em muito auxiliará para a preservação do farto material que foi rigorosa e pacientemente coletado, analisado e 
mapeado por atlas linguísticos, a exemplo do Atlas Linguístico do Brasil, publicado em 2014", cujos dados podem ser reaproveitados para o aprimoramento dos dicionários, por meio da ampliação de informações da diversidade linguística que permeia nosso país, fazendo com que falantes do português possam se familiarizar com as formas alternantes aqui existentes e conhecedores (e, talvez, produtores) do caráter multidialetal do português brasileiro.

Daniela Faria Grama e Neubiana Silva Veloso Beilke, com o texto Linguística Aplicada E Lexicografia Pedagógica: intersecções possíveis por meio da Linguística de Corpus, abordam questões relacionadas à Linguística Aplicada e à Lexicografia Pedagógica, à luz da Linguística de Corpus. Com efeito, demostram que, por meio de um corpus de Lexicografia Pedagógica constituído por artigos científicos, no qual foi realizada a busca do termo "dicionário pedagógico", as concordâncias geradas pela ferramenta computacional utilizada revelaram as características idealizadas para um dicionário pedagógico, que, entretanto, não são consideradas por dois dicionários analisados.

Já Davi Albuquerque, em As relações entre ecolexicografia e lexicografia pedagógica versa sobre as contribuições que a ecolexicografia pode oferecer à Lexicografia Pedagógica. Antes, contudo, trata sobre uma nova abordagem que despontou nos estudos da linguagem: a Ecolinguística, definida por Einar Haugen, em 1972, como sendo as relações existentes entre língua e meio ambiente, a grosso modo, postulando duas concepções: "uma que se preocupa com as relações entre as línguas, e as línguas com o meio ambiente, outra que investiga as inter-relações existentes em uma língua". Por sua vez, a inovadora ciência da Ecolexicografia foi proposta por Manoel Soares de Sarmento, em 2000, "procura fornecer subsídios para o ecolexicógrafo elaborar tanto dicionários, quanto definições distintas do que a Lexicografia vem oferecendo até o momento", uma vez que oferece uma nova visão do mundo: a ecológica, e uma nova consciência perante as palavras, qual seja, do seu poder tanto para o falante quanto para o mundo. 


\section{Um pouco de taxonomia, macro e microestrutura}

Sobre dicionários, Cíntia Voos Kaspary, com o texto Uma proposta de taxonomia para dicionários monolíngues para aprendizes de FLE, propõe uma taxonomia de dicionários monolíngues para a língua francesa, que reflete as diferenças apresentadas por essas obras lexicográficas e os aspectos funcionais e linguísticos empregados em sua elaboração, baseando-se em Bugueño (2014), que os classifica a partir de três axiomas: (i) “o fato de que é impossível realizar uma classificação que contenha todos os tipos de dicionário, pois o surgimento de novas obras lexicográficas é constante"; (ii) a afirmação de que "a classificação taxonômica permite uma melhor avaliação de diferentes dicionários comparada a uma classificação tipológica" que "permite o estabelecimento de genótipos lexicográficos, isto é, são apresentados de forma clara traços definidos e caracterizados em função de uma matriz de traços" e (iii) a aplicação, em conjunto, dos critérios funcional e linguístico. Desse modo, a autora apresenta uma taxionomia ampliada com o objetivo de tentar "unir as obras lexicográficas para falantes nativos e para aprendizes de francês em um mesmo sistema, para que seja possível uma visão mais geral do cenário lexicográfico francês disponível".

Em relação à estruturação macro e microestrutural dos dicionários, Thiago Leonardo Ribeiro e Vera Maria Ramos Pinto apresentam uma análise contrastiva de quatro dicionários selecionados pelo PLND (2012) dos Tipo 2 e 3, com o texto Dicionário em sala de aula: análise da macro e microestrutura textual, com o escopo de analisar os critérios utilizados pelos lexicógrafos na sua elaboração e sua adequação ao públicoalvo em questão. Como resultados, alegam que os dicionários analisados do Tipo 2 procuram satisfazer seus consulentes, ou seja, alunos do ensino fundamental I, com faixa-etária dos 6 aos 10 anos, visto que empregam uma linguagem adequada na redação dos verbetes e a organização das entradas propicia o seu entendimento. Já os 
dicionários analisados do Tipo 3 são direcionados a jovens de 11 a 15 anos e possuem características de minidicionários, cujos verbetes apresentam informações linguísticas variadas, uma linguagem impessoal, muitas vezes técnica e especializada que, acreditam, seja inacessível ao público-alvo. Seu julgamento final é de que as obras analisadas "são de boa qualidade e estão em consonância com os critérios da Lexicografia Pedagógica no que diz respeito à organização da macro e microestrutura".

\section{Um pouco de análise de dicionários para/de aprendizes de língua estrangeira (LE)}

Um dos objetos de estudo da Lexicografia Pedagógica é, justamente, o dicionário para aprendizes de língua estrangeira. Em Verdade e mito dos dicionários de aprendizes do inglês e do alemão, Laura Campos de Borba e Félix Bugueño Miranda discutem se dois dicionários de aprendizes, nas línguas inglesa e alemã, estão associados ao processo de ensino-aprendizagem de uma língua estrangeira, visto acreditarem como inerente à elaboração dessas obras essa atrelagem. Para tanto, analisam a maneira como a língua-alvo é descrita nesses dicionários, a partir de "documentos que contêm diretrizes sobre o seu ensino-aprendizagem (English Profile (2011) e Profile Deutsch (2005), respectivamente)". Após detalhado exame, concluem que não existe correspondência entre os recursos lexicais utilizados e os níveis de aprendizagem; sendo assim, os "documentos supracitados não são úteis para a compilação de dicionários", que, por sua vez, "refletem a norma em uso, mas, evidentemente, não estão atrelados aos documentos norteadores de ensinoaprendizagem do inglês e do alemão", embora os repertórios lexicais tenham sido considerados "bons" sob diversas perspectivas, devido à Linguística e suas áreas conexas.

Virginia Sita Farias, com o texto Descrição semântica em dicionários para aprendizes de espanhol: o problema das palavras gramaticais, avalia paráfrases definidoras, exemplos 
e pós-comentários que se apresentam em verbetes de palavras gramaticais em dois dicionários de espanhol com o intuito de verificar se essas informações semânticas levam em consideração o perfil do usuário, a definição tipológica do dicionário e sua(s) função(ões). “Os resultados obtidos apontam para uma discrepância entre as informações disponíveis nos verbetes das obras analisadas e as reais necessidades dos consulentes". Ademais, a autora conclui que a concepção dos dicionários avaliados não responde “à definição tipológica do genótipo lexicográfico em questão e tampouco corresponde a um perfil específico de usuário".

No texto El componente cultural en los artículos lexicográficos del léxico de la bebida, de la gastronomía y de la hostelería en diccionarios de ELE, Glauber Lima Moreira examinou seis verbetes extraídos do Diccionario para la Enseñanza de la Lengua Española para Brasileños, de 2003, e do Diccionario de Español para Extranjeros, de 2002, dos subcampos lexicais "bebida", "gastronomia" e "hospedaria", do âmbito do "turismo". O autor deduz que, das análises realizadas, as definições e os exemplos das entradas não registram, ou quando o fazem é de maneira superficial, o componente cultural necessário para uma mais completa compreensão do consulente-aprendiz da palavraentrada em língua espanhola para que possa aprender a maneira de viver, relacionarse, atuar, ver e explicar o universo daquela comunidade linguística em estudo. Ademais, acrescenta que "essas informações pragmáticas ajudam no processo de comunicação em outra língua com mais eloquência".

No que diz respeito à equivalência em dicionários bilíngues, Rejane Bueno e Adja Balbino de Amorim Barbieri Durão, no texto El tratamiento de la equivalencia verbal en diccionarios (semi)bilingües para el aprendizaje de la lengua española, analisam os equivalentes tradutórios em entradas verbais de um dicionário (semi)bilíngue, no caso, o Diccionario para la Enseñanza de la Lengua Española para Brasileños, edição de 2000, mais conhecido como Señas, partindo da noção de ensinamento comunicativo das línguas e da autonomia produtiva, com o escopo de verificar se essa escolha de 
equivalência obedece a critérios sistemáticos e coerentes a partir de uma perspectiva linguística e lexicográfica e se leva em consideração o consulente para o qual a obra foi dirigida. Ressaltam que a questão da equivalência é um dos aspectos mais estudados na Lexicografia bilíngue e deduzem, da avaliação crítica realizada, que "a eleição dos equivalentes [...] obedece a lógica do dicionário monolíngue de aprendizes de LE, sem muitas problematizações, e não a lógica do dicionário que envolve duas línguas, como seria o esperado" e tampouco segue um Programa Constante de Informações para seu estabelecimento.

\section{Um pouco de fraseologismos}

Em relação à dificuldade que o aprendiz de língua tem em aprender, apreender, fixar e utilizar expressões idiomáticas, colocações, locuções, provérbios, os fraseologismos interessam bastante à Lexicografia Pedagógica e seus pesquisadores estão sempre entretidos com uma nova complexidade que surge a cada passo que se dá, por exemplo, na feitura de um dicionário mono ou bilíngue.

Nesse sentido, o trabalho de Ivonne Jordan de Mogendorff e Cleci Bevilacqua, intitulado Prende la computadora, usa el diccionario de colocaciones de sustantivo + verbo y mejora tu aprendizaje apresenta uma proposta inicial de dicionário pedagógico bilíngue eletrônico de colocações formadas por substantivo + verbo na língua espanhola, com o intuito de amenizar as dificuldades que falantes do português encontram no estudo do espanhol, dada à similitude existente entre essas duas línguas, e melhorar, consequentemente, seu domínio colocacional e sua competência comunicativa. De fato, constataram "a importância da Fraseologia e das colocações especialmente, como peças fundamentais do ato comunicativo. Nesse sentido, no contexto de ensino de língua espanhola no Brasil, observaram que não se dá a devida atenção pedagógica às colocações divergentes entre as duas línguas e, por desconhecimento, os alunos transferem as colocações da sua língua materna para a língua espanhola". 
Nessa mesma linha, ou seja, de proposta de dicionário bilíngue voltado para os fraseologismos, trata o texto Protótipo de verbete de um dicionário bilíngue pedagógico para aprendizes brasileiros de espanhol com foco nas unidades fraseológicas escrito por Arelis Felipe Ortigoza Guidotti, no qual a autora apresenta um modelo de verbete para o campo semântico da alimentação, na direção espanhol-português. A nomenclatura dessa proposta de repertório linguístico foi extraída de livros didáticos do Programa Nacional do Livro Didático (PNLD) 2011 e 2012, enfatizando-se, neste relato, o registro das unidades fraseológicas (UF). Com base na Lexicografia Bilíngue, a autora buscou “elaborar um produto que tivesse fins pedagógicos e que envolvesse as contribuições advindas da Fraseografia", que "contemplasse o registro de UFs, exemplos de uso, informações colocacionais ou possibilidades combinatórias, assim como informações pragmáticas que incluíssem notas explanatórias ou observações que o consulente deveria considerar nas suas produções em língua espanhola".

Já Jacqueline Vaccaro Teer, com o texto A lematização de expressões idiomáticas em dicionários para aprendizes, defende a inserção de fraseologismos, principalmente as expressões em dicionários de aprendizes de língua espanhola. Para isso, analisou dois intervalos lemáticos de cem folhas cada no dicionário Señas, já especificado anteriormente nesta apresentação. As mesmas expressões idiomáticas, posteriormente, foram buscadas no Diccionario Salamanca de la lengua española, de 1996, monolíngue, portanto, com o objetivo de contrastar esse tipo de inserção lexical nessas duas obras. Concluindo, diz que: “Os dicionários analisados neste trabalho apresentam pontos positivos e negativos em relação à inserção das EIs e às informações dadas sobre elas. O dicionário SEÑAS traz uma equivalência em português que colabora para a compreensão e produção por parte dos seus consulentes, quando empregada adequadamente. Já o dicionário SALAMANCA inclui as EIs em todos os elementos que as compõem, remetendo àquele que traz a paráfrase definitória. Por outro lado, percebe-se que nem sempre esses dicionários 
trazem marcas de uso e que, às vezes, essas informações não são suficientes para determinados casos".

\section{Um pouco de marcas de uso, semântica cognitiva e língua de sinais}

O texto Marcação de verbetes sobre homossexual masculino em dicionários escolares, de Hugo Leonardo Gomes dos Santos, Antônio Luciano Pontes e Pedro Henrique Lima Praxedes Filho, reporta a investigação realizada em dicionários escolares do Tipo 3 do Programa Nacional do Livro Didático de 2012 concernente as marcas de uso utilizadas por essas obras para a indicação de restrições e os contextos de uso de unidades lexicais relacionadas ao campo do "homossexual masculino". Foi realizado um levantamento de 11 entradas relacionadas ao referido campo, num total de 44 verbetes extraídos de cinco desses dicionários. A começar das definições escolhidas, elaboraram "redes de fluxo de sentido, redes medioestruturais" e analisaram "o posicionamento das marcas de uso empregadas por cada dicionário, nas redes elaboradas, e os padrões de marcação de cada palavra". Em conclusão, chegaram aos seguintes resultados: (i) a marca mais frequente foi aquela que se refere ao uso pejorativo e indica contextos discriminatórios nos quais essas palavras são utilizadas, e (ii) entradas que receberam a rubrica de "bicha", "baitola" e "maricas", "estão posicionadas às margens da rede e

o fluxo de sentidos converge dessas palavras para as palavras não marcadas "gay" e "homossexual".

Larissa Moreira Brangel, com o texto A semântica cognitiva como ferramenta de otimização das definições tipo whole-sentence, discute as possibilidades de contribuição que a semântica cognitiva pode oferecer para a criação de condições mais favoráveis de redação para as definições lexicográficas do tipo whole-sentence. Ademais, demonstra, na prática, uma possibilidade de se estabelecer essa relação, baseando-se nos princípios da semântica de frames e a base de dados da FrameNet. Seu objetivo principal é "contribuir para que a elaboração de paráfrases voltadas para crianças seja 
uma atividade amparada por bases mais teóricas e menos especulativas", discutindo "pontos de contato entre as whole-sentence definitions e a semântica cognitiva, estreitando, assim, as relações entre a teoria semântica e a prática lexicográfica".

Já o texto Ordem Visográfica - colocando os dicionários de línguas de sinais em ordem, escrito por Leandro Andrade Fernandes e Mariângela Estelita Barros apresenta uma proposta de arranjo de entradas em dicionários de línguas de sinais numa ordem linear e alfabética, denominada pelos autores de "ordem visográfica", que faz uso do sistema brasileiro de escrita das línguas de sinais, ELiS. Este último é o sistema de escrita para as línguas de sinais que apresenta “[...] a primeira possibilidade no mundo de elaboração de dicionários semasiológicos com entradas em línguas de sinais organizadas de maneira estritamente alfabética linear. Isso porque esse sistema de escrita representa sistematicamente os principais fonemas das línguas de sinais e os organiza linearmente. Na ELiS, os visografemas são dispostos em sequência linear em uma palavra, ou seja, um visografema após o outro".

\section{Um pouco de entrevista}

O último texto deste número, intitulado Lexicografía Pedagógica/Didáctica: entrevista con María Teresa Fuentes Morán, traz uma conversa com uma das mais representativas lexicógrafas no cenário mundial da atualidade. Nele, discutem-se importantes questões acerca da Lexicografia Pedagógica, a começar pela própria terminologia empregada nessa área: se Lexicografia Pedagógica ou Lexicografia Didática. Em seguida, Teresa Fuentes discute o objeto de estudo dessa ciência, assim como em relação à funcionalidade de contextos em dicionários, à reflexão entre dicionários passivos e ativos, à tecnologia envolta ao labor do lexicógrafo.

María Teresa Fuentes Morán é licenciada em Filologia Hispânica (Universidad Complutense) e doutora em Linguística (Universität Augsburg). Iniciou a trabalhar na Universidade de Salamanca em 2000, e desde 2006 é Professora Titular do 
Departamento de Tradução e Interpretação (Facultad de Traducción y Documentación). Seus pontos de investigação são os aspectos aplicados de língua espanhola e linguística, principalmente no âmbito da Lexicografia e da Tradução. Além disso, é especialista em planejamento e gestão de projetos de cooperação para o desenvolvimento no campo da educação e especialista universitária em ambientes virtuais de aprendizagem.

Como se percebe, os autores que abrilhantam esta edição basearam seus textos em teorias sólidas, tais como a Lexicologia e a Lexicografia, a Lexicografia Pedagógica, a Lexicografia Bilíngue, a Linguística Aplicada, a Dialetologia, a Linguística de Corpus, a Linguística Cognitiva, a Fraseologia, entre outras.

Esperamos que todos os que venham a ler os artigos aqui selecionados possam se deliciar com a leitura, amadurecer com as reflexões que serão propiciadas e dar continuidade aos estudos da Lexicografia Pedagógica para que seja possível alavancar essa área tão produtiva e fértil em nosso país.

Claudia Zavaglia (UNESP/S. J. Rio Preto) Odair Luiz Nadin (UNESP/Araraquara)

\section{Referências bibliográficas}

TEIXEIRA, M. C. A designação de "Lexicografia Pedagógica”. Interfaces. Vol. 6, n. 3 (dezembro), p. 29-35, 2015.

MOLINA GARCÍA, D. Fraseología bilingüe: un enfoque lexicográfico-pedagógico. Granada: Editorial Comares, 2006. 